\title{
Research on the Symbiosis Between Public Art and Economy
}

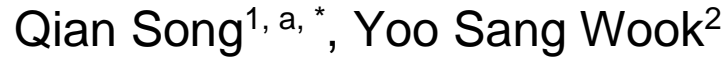 \\ ${ }^{1}$ Marine Convergence Design Pukyong, National University Busan, Korea \\ ${ }^{2}$ Department of Industrial Design Pukyong, National University Busan, Korea \\ *, a 467226543@qq.com
}

Keywords: Geo cultural; Economy; Public art.

\begin{abstract}
Public art is one of the high frequency words in the art world in recent years. Traditionally, public art is often understood as a statue in the square, a permanent art on street or relief sculpture in a government building. And the public art that we're talking about today is beginning to be democratized, interactive, it is becoming a concept of contemporary art. This paper focuses on the relationship between public art and economy. Take the bay lights, the world's largest public art work, as example. Analyze its funding sources and benefits. This paper also discusses how to improve the regional economy through public art.
\end{abstract}

\section{The Concept of Public Art}

Public art refers to the art works placed in public space and open to the public, which can be created in any medium. There are three recognized basic attributes and elements of public art, that is, publicity, artistry and locality. This is also a criterion for distinguishing between public art and other art categories. In the academic circles, "Roosevelt's new deal" was generally regarded as the starting going of public art research in 1930s. In fact, the concept of public art has not yet formed in this period, but it has already produced the embryonic form of public art and stimulated the growth of the concept of public art. In this period, the discourse power of public art lies in the state and government institutions, mainly for the purpose of social security and maintenance of social stability, aims at the architectural decoration of the federal government by using the means of employment. In 1959, Philadelphia, became the first city to implement the plan of percent for art, that is to say, no less than one percent of the building budget was allocated to public art. It marks the formation of the government's thinking foundation for public art planning, and enables developers to have certain decision-making power for public art. In 1965, the establishment of "National Art Committee" and "National Art Fund" in the United States further changed the existence of art as a form of architectural decoration. At this stage, public art has been the concern of the public as an independent individual. In this period of public art, artists began to master the right to speak, but the problems also followed. The works of these artists are mostly the simple magnification of the existing works in the museum, which is separated from the aesthetic taste of the people and lead the reform of the policy. With the expansion of public consciousness of democracy, "public art" gradually began to tend to the definition of "public". In 1974, the American Art Foundation adds the provision of "public art should be coordinated with its place". Then, at the end of the 80s, the concept of "new genre public art" was created. It has the attribute of combination of function and art. Advocates hope that new genre public art is both a work of art and a form of art that is integrated with citizen life.

\section{Analysis of Funding Sources of Public Art-Take the Bay Lights as an Example}

Nicholas Baume, chief curator of the American Public Art Foundation, said that the fund in 2015 was $\$ 5,500,000$ which is mainly comes from income of curatorial advisory service related to public art and organization of special activities, followed by donations of corporate and foundation, and only $1 \%$ of the municipal and federal government funds.

As one of the largest public works of art in the world, the bay lights (figure 1, figure 2) which is installed on the San Francisco New Bay Bridge in 2013, has a very complex source of funding. The 
initial cost of $\$ 8,000,000$ was raised by private donations. As a non-profit organization that combines art and technology, ZERO1 is the official financial sponsor of the project. The project uses about $\$ 30$ of electricity per day, or a total of $\$ 11,000$ a year. During the three months' temporary installation, these expenses were paid by a private solar energy investment company in the form of solar energy credit. In July 2014, the "illuminating art" announced that it was working with Tilt.com to launch a crowd raising campaign of $\$ 1,200,000$ to keep lighting the bay until 2026. However, the crowd raising campaign was not so smooth. Then the organizers focused on the bigger donors and eventually raised $\$ 4,000,000$ to install long-term devices. The Bay Area tolling Bureau, which is responsible for overseeing the bridge, agreed to grant $\$ 250.000$ a year for maintenance and power supply.

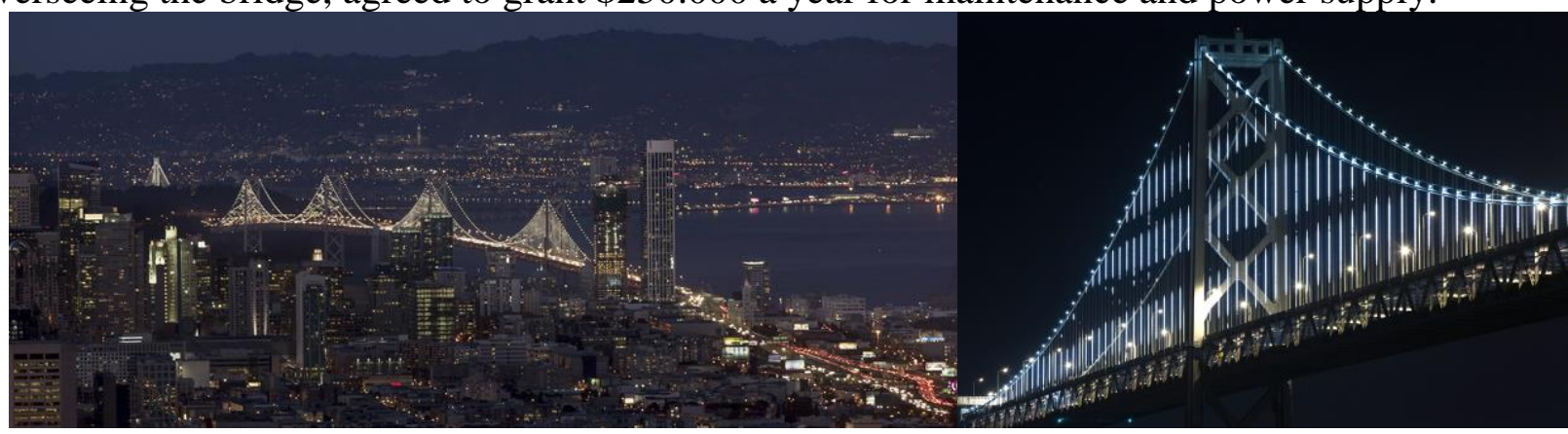

Figure 1 < the bay lights>

Figure $2<$ the bay lights>

It can be seen that the fund source of public art is not simply replied on one department. All levels from design, production, installation, usage and maintenance are all need investment. The real purpose of these inputs is also because public art can really boost regional economies. Let's take the Bay Lights as an example. It has already brought over $\$ 100,000,000$ in revenue to the local places.

\section{The Process of the Influence of Public Art in Society}

The spread of a regional culture is divided into the following stages under the condition of perfect infrastructure; first of all, the formulation and introduction of policies, which mainly determines the source of funds and the proportion of investment; secondly, the visual image of the intervention, which is mainly implement propaganda in the television, network and other media to enable the public have an initial impression of the region and enhance the visibility of the region; thirdly, putting public art works at the main nodes in the city, which can let the masses participate in the construction of regional culture. According to the theory provided in the book "the image of the city", a common research of Harvard University and MIT, the elements of urban impressions are divided into five levels: road, edge, area, node and sign. If the city park or the art museum is regarded as the key node, then the public art behavior and the works will become the "core" in the node as the identification mark. Wang Zhong, a teacher at China Central Academy of Fine Arts in China, once proposed the idea of "60\% public art". The significance of this is that the present public art has not been done by the artist simple, but by the public who works together in the process of interaction with the works of art after the completion of the artist. From this we can see that the new feature of public works is to arouse people's introspection while paying attention to the interactive relationship with the masses. The final stage is to test people's preferences so as to design, launch and sell cultural products. From the observation of Table 1, it can be said that public art plays a connecting role in the dissemination of regional image. Good public art behavior is a key step in the city image communication.

Judging from the process of public art review in the United States (Table 2), the general public can also have a certain impact on the decision-making power of public art. In the process of polling and conference discussion, art lowered its level and begin to interact with the masses, which promoted the relationship between public art and the public. 
Table1 the stage of spreading of regional culture

\begin{tabular}{|c|c|}
\hline Number & Stage \\
\hline 1 & Infrastructure \\
\hline 2 & The introduction of policy \\
\hline 3 & Visual image design and delivery. \\
\hline 5 & Public art and design \\
\hline 5 & Cultural product design and sale \\
\hline
\end{tabular}

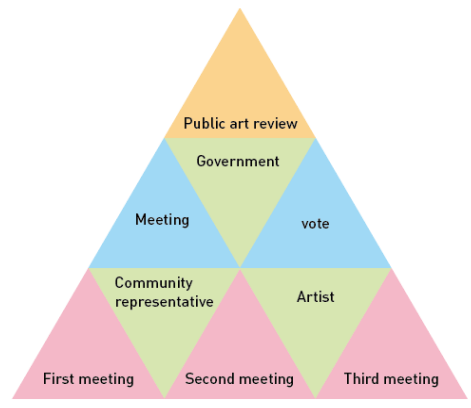

Table 2. the process of public art review

\section{Four Levels of The Relationship Between Public Art and Economy}

We may think like that, the reason that makes you come to a strange city again is definitely not the high buildings, but those of the humanities. After the time of the postindustrial era, the construction mode of skyscrapers and commercial planning areas representing the high economic growth mode is gradually replaced by the urban planning thinking with emphasis on geo culture. The public art plays a key role in changing the situation of "thousands of cities with only one appearance".

Let's look at a set of data. In April 2nd, 2018, according to a new survey published by the Economic Analysis Bureau of the United States Department of Commerce and the NEA and data collected over the past 1998 to 2015 years, we can have concluded that the arts industry contributes $\$ 763,600,000,000$ a year to the Unites States which is accounted for $4.2 \%$ of the gross domestic product. This can prove that there is a close relationship between the art industry and the economy, and it can also contribute to the development of the regional economy.

Therefore, public art can improve the urban economy through the four ways.

1) Use new materials to save energy

Let's take The Bay Lights (Figure 1), the largest single piece in the world, as an example. It adopts the latest LED light source and manipulates it with computer programming to change in real time. At first it was just a three-month temporary lighting show. The ultimate reason for its permanent placement is that such a huge lighting device consumes only $\$ 30$ per night but

2) Use interactive means to drive the surrounding economy

Holland artist Hoffman's rubber duck (Figure 3) was exhibited at the Victoria Harbor (Figure 4) in Hong Kong from May 2nd, 2013 to June 9th, 2013. This is the first time for rubber duck to exhibit in Chinese waters, which attract more than one million people in the first week. By the end of August 2014, rubber duck has been exhibited in 22 cities in 13 countries. There are even reports that rubber duck in any city with a lake and sea will be sought after, and the theory of "Neoteny" is used to analyze the reason for the love of rubber duck from a psychological perspective. Although Hoffman insists that his art is off public interest and no fee will be charged in exhibition, so many spectators will have a positive effect on the surrounding economy. It is reported that the revenue generated during the exhibition is more than twelve million dollars. 


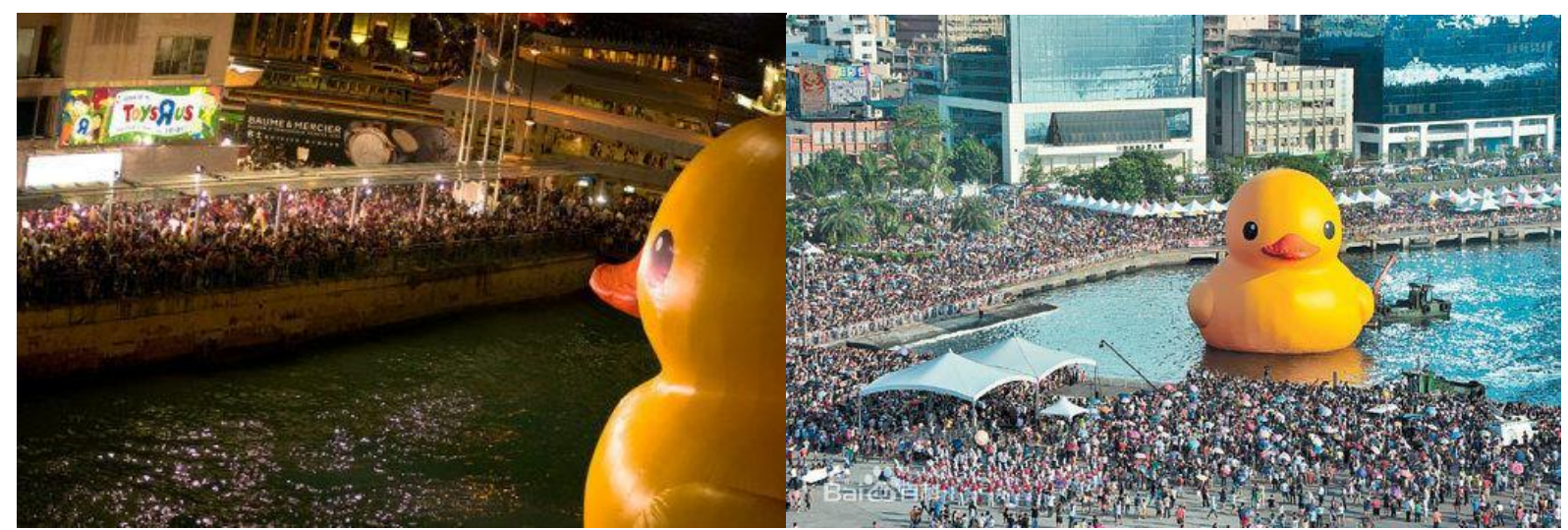

Figure $3<$ rubber duck >

Figure $4<$ rubber duck >

3) Improve city function and discover new economic growth point

If the art is now used to decorate or improve the waterside environment, the most notable 2018 public art project in Europe is "Light up the Thames River". This is also the lighting project of the "Current" (Figure 5 Figure 6 Figure 7) presented by the American Lightning artist Leo Villareal and LDS architects in London. Leo Villareal creates a series of new light landscape with interactive effects by using the dynamic lighting of computer programming with the flow of Thames River and the movement of pedestrians on the bridge. From this picture we can see the panorama of the riverbank line after the transformation. At present, the most lighting settings on bridges still retains the design of years ago, which accumulate many problems such as too dazzling light, too much light source, etc. With the most advanced LED lighting technology, the average power consumption can be reduced by $50 \%$ to $70 \%$ in one bridge. The adoption of new facilities has saved more maintenance costs for local management departments. The London government says it is not only the redesign of some of the most Landmark Bridges in London, but also the development of a wider public area on both sides of the bridge, providing a more friendly and safe walking environment. They also encourage the public to participate in various urban activities along the river.

This is the public art that improves the function of the city.

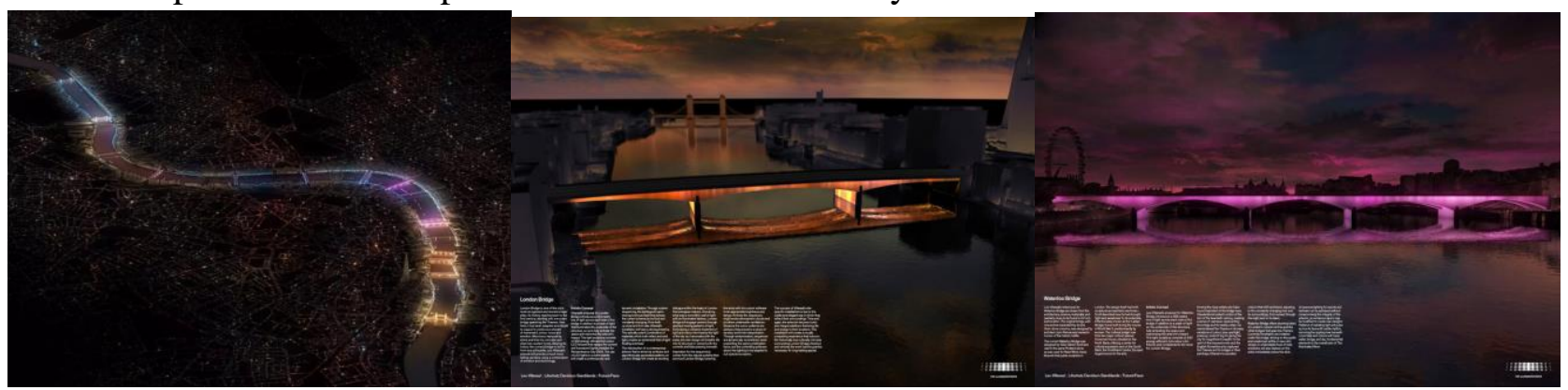

Figure 5. Current project

Figure 6. Current project

Figure 7. Current project

4) Improve taste of city place and added value of industry

Although a small town with a population of only six million, there will be one million people go to a vegetable market every week. This example also occurs in a port city, Rotterdam, Holland. There is a 3D projection mural (Figure 8) with 11000 square meters inside the Markthal (Figure 7), which is the largest art in Holland and undoubtedly the biggest feature of the vegetable market. In fact, this starts with the new regulation of EU derivative environmental regulations: all cooked food must be sold in the covered space. After the EU proposed an amendment to the bill, the Rotterdam municipal government decided to build an indoor market of surface significance to accommodate vendors selling cooked food. There is a transparent glass curtain wall outside the Markthal to reflect the entire view of the city and sea. The arched building part of the market is made up of 228 apartments, that is to say, apart from business and entertainment functions, it also has residential functions. Markthal is the first building in the world to combine residential and artwork and market. Now, it has become a new landmark in Rotterdam. This is a case in which public art has increased the added value of the original business format and increased the attractiveness of the city. 


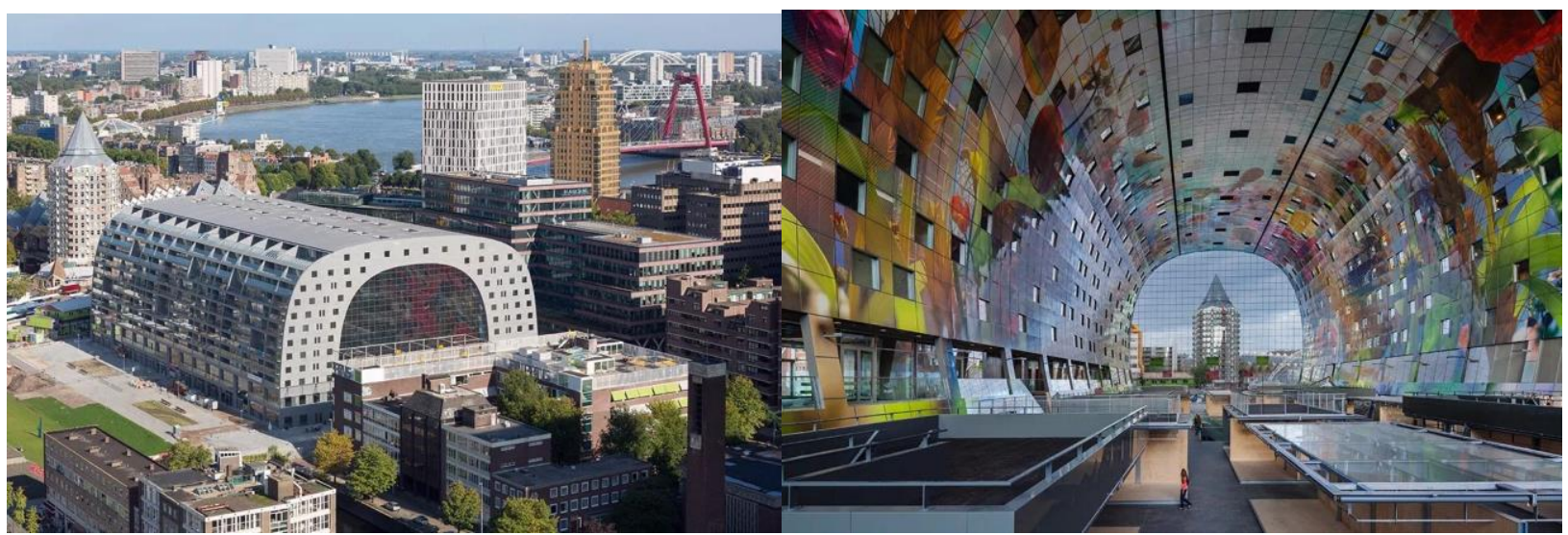

Figure 8. 3D projection mural

Figure 9. Attractiveness of the city

\section{Conclusion}

Through the above research, we can find that, first of all, the connotation of public art is not the traditional identity and landmark of the "financial cattle" like the Wall Street in New York. Public art in the new era emphasizes more on the uniqueness of the city, highlighting regional culture, paying attention to cultural heritage and harmonious development with the city. The most important thing is to improve the economy through artistic means, while avoiding the similarity of artistic behavior and advertising behavior. Good public art can not only bring beauty to the public, but also bring space for the masses to think. Secondly, the public art no longer emphasizes the pure pursuit of the interests of the developers, but take comprehensive consideration of the urban economy, culture, society, ecological environment, the acceptance and participation of the people. To develop public art in cities is an effective way to promote regional culture and social field and further develop regional economy.

\section{References}

[1]. http://www.qdaily.com/articles/35738.html

[2]. https://www.uapcompany.com/news/ make art public -louise-martin-chew?lang=cn

[3]. https://www.uapcompany.com/news/ Public art: creativity is the catalyst for economic success.?lang $=\mathrm{cn}$

[4]. <The discourse transformation of art in public space -- the changes of the concepts of public arts.> ZhiHong Zhao

[5]. <The development and evolution of Chinese public arts policy> He Yuan

[6]. <Definition of public concept in public art.--Research on Chinese public art discourse.> He Li 